\title{
Grafen Nanotabaka Katkılı Alümina Esaslı Kompozit Üretimi ve Karakterizasyonu
}

\author{
Ismail Yıldız ${ }^{1 *}$ Atilla Evcin ${ }^{2}$, Emine Çelmeli ${ }^{3}$, Ismail Gündüz ${ }^{4}$ \\ ${ }^{1 *}$ Afyon Kocatepe University, Iscehisar Voluntary School, 03750, Afyonkarahisar, Turkey orcid id:0000- 0002- 9207-591x \\ iyildiz@aku.edu.tr \\ ${ }^{2}$ Afyon Kocatepe University, Materials Science and Engineering Department, 03200, Afyonkarahisar, Turkey orcid id: 0000-0002- \\ 0163-5097 evcin@aku.edu.tr \\ ${ }^{3}$ Afyon Kocatepe University Graduate School of Natural and Applied Sciences Department of Nanoscience and Nanotechnology, \\ 03200, Afyonkarahisar, Turkey (ORCID: 0000-0003-0921-3881), eminecelmeli07@gmail.com \\ ${ }^{4}$ Afyon Kocatepe University Graduate School of Natural and Applied Sciences Department of Nanoscience and Nanotechnology, \\ 03200, Afyonkarahisar, Turkey (ORCID: 0000-0001-9345-3137), igunnduz@gmail.com
}

(İlk Geliş Tarihi 24.04.2021 ve Kabul Tarihi 06.05.2021)

(DOI: 10.29228/JCHAR.51259)

ATIF: Yıldız I., Evcin A. Çelmeli E., Gündüz I., Grafen Nanotabaka Katkılı Alümina Esaslı Kompozit Üretimi ve Karakterizasyonu, Journal of Characterization, Vol 1 (2), 71-80, 2021. http://dx.do6.org/10.29228/JCAR.51259

Öz

Bu çalışmada grafen nanotabaka (GNP) katkılı alümina esaslı nanokompozit malzemelerin karakterizasyon özellikleri araştırılmıştır. Nanokompozit malzemelerin üretiminde toz metalürjisi yöntemi kullanılmıştır. $\% 1,2$ ve 3 GNP katkılı alümina esaslı tozlar bilyeli karıştırıcıda 24 saat süreyle homojen bir şekilde karıştırılmıştır. Karışan tozlar tek eksenli preste dikdörtgen hacimli kalıp içerisine dökülerek yaklaşık olarak 200 bar basınç altında şekillendirilmiştir. Elde edilen numunelere kapalı firın ortamında $1300{ }^{\circ} \mathrm{C}$ sıcaklıkta 4 saat süreyle ısıl işlem uygulanmıştır. Bu işlem sonrasında ise sırasıyla \% su emme, bulk yoğunluk ve \% gözeneklilik testlerinin yanı sıra mekanik test olarak basma testi yapılmıştır. Yapı içerisindeki tane boyutu ve dağılımları ise SEM-EDX analizleri gerçekleştirilerek belirlenmiştir.

Anahtar Kelimeler: Grafen, alümina, bulk yoğunluk.

\section{Production and Characterization of Graphene Nanoplatelet-Doped Alumina-Based Composite}

\begin{abstract}
This study, investigated the characterization properties of graphene nanoplateklet (GNP)-doped aluminabased nanocomposite materials. The Powder metallurgy method has been used in the production of nanocomposite materials. Alumina-based powders with 1, 2, and 3\% GNP were mixed homogeneously in
\end{abstract}




\section{Journal of Characterization}

a ball mixer for 24 hours. The mixed powders are poured into a rectangular mold in a uniaxial press and formed under approximately 200 bar pressure. The samples were heat-treated at $1300{ }^{\circ} \mathrm{C}$ for 4 hours in a closed oven environment. After this process, density, $\%$ water absorption, bulk density, and \% porosity tests were performed, as well as compression test as mechanical test. Grain size and distribution within the structure determined by SEM-EDX analysis.

Keywords: Graphene, alumina, bulk density.

\section{Giriş}

Toz metalürjisi (TM), metal ve seramik esaslı çok küçük tozları birbirine bağlayarak parça hâline getirme işlemidir. Aynı zamanda bu tozların geometrik şekle sahip olması için bir kalıp içerisine dökülüp, belirli bir basınç altında şekillendirildikten sonra ergime sıcaklığı altında istenilen parça haline dönüştürülmesi yöntemidir [1-3]. Toz metalürjisi, biyomedikal uygulamalarda diş protezleri, ortopedik ürünler, seramik malzemelerin üretimi, metal esaslı alaşımlarda makine parçaları, şarj edilebilir piller, yüksek sıcaklık filtreleri, jet motoru parçaları gibi birçok uygulama alanına sahiptir [4,5]. Bunlar arasında seramik esaslı malzemeler önem kazanmış ve alümina esaslı kompozit malzemeler ön plana çıkmıştır [6].

Alümina, seramik sektöründe en çok kullanılan seramikler malzemeler arasında yer almaktadır $[7,8]$. İleri özellikleri sahip olması nedeniyle, yüksek hızlı kesme aletlerinde, kimyasal ve elektrik izolatörlerinde, aşınmaya dayanıklı parçalarda veya diş implantlarında gibi önemli kullanım alanları vardır $[9,10]$. Bununla birlikte, yapı itibariyle monolitik bir formda olduğundan, bazı durumlarda yüksek performansa sahip yerlerde istenilen gereksinimleri karşılayamadığı durumlar ortaya çıkmaktadır. Bu nedenle, gelişmiş özelliklere sahip yeni nanokompozitler geliştirmek için grafen, silisyum oksit, silikon gibi malzeme takviyeleri ile kullanım alanlarını genişletmektedir [11-13].

Grafen, özellikle metal, seramik ve polimer esaslı malzemelerde takviye edici malzeme olarak katıldığında yüksek özgül yüzey alan, kimyasal stabilite, yüksek dayanım (1 TPa elastik modülü and 125 GPa kırılma dayanımı), termal ve elektrik iletkenlik gibi özellikler sergilemektedir [14-16]. Alümina gibi ileri seramik malzemeler düşük kırılma tokluklarından dolayı sınırlı uygulamalarda kullanılmaktadır. Alümina esaslı malzemeler grafen takviyesi ile mevcut özelliklerini geliştirmektedir. Bu özellikler arasında düşük yoğunluk, yüksek sıcaklık dayanımı, isı ve elektriksel yalıtımla birlikte kimyasal stabilite yer almaktadır [17,18].

Bu çalışmada grafen katkılı alümina esaslı seramik malzemelerin toz metalürjisi yöntemi ile üretimi yapılmıştı. Elde edilen malzemelere karakterizasyon çalışmaları gerçekleştirilmiş, mekanik test olarak basma testi ve morfolojik analiz olarak SEM-EDX yapılmıştır. Sonuçlar literatürle karşılaştırılarak önemi vurgulanmıştır.

\section{Malzeme ve Metot (Material and Methods)}

\subsection{Malzeme}

Çalışmada kullanılan GNP tozlar Nanografi Nano Technology firmasından temin edilmiştir. Saflığ $\%$ 99, boyutu $3 \mathrm{~nm}$, yüzey alanı $320 \mathrm{~m}^{2} / \mathrm{g}$ ve çapı $1.5 \mu$ m'dir. Alümina tozlar ise Nanokar firmasından temin edilmiştir. Boyut 1-100 $\mu$, saflık ise \% 99,7’dir.

$\% 1,2$ ve 3 oranlarında GNP alümina tozlarla birlikte kapalı kutu içerisinde bilyeli karıştırıcıda 24 saat süreyle karıştırılmıştır. Elde edilen alümina esaslı karışım tek eksenli pres kullanılarak dikdörtgen prizma şekilli kalıpta yaklaşık olarak 200 bar basınç altında şekillendirilmiştir. Ortaya çıkan numunelerin dayanımlarını arttırmak için kamara tip fırında $1300{ }^{\circ} \mathrm{C}$ sıcaklıkta 4 saat süre boyunca 1 sıl işlem gerçekleşmiştir. Bu işlem sonrasında numunelere sırasıyla \% su emme, bulk yoğunluk ve \% gözeneklilik testleri yapılmış, mekanik test olarak ise basma testi gerçekleştirilmiştir. Morfolojik analiz olarak SEM- 
EDX yapılarak yapı içerisindeki tane boyutu ve dağılımları incelenmiştir. Bu yapılan işlemler aşağıda yer alan akış diyagramında gösterilmiştir (Şekil 1).

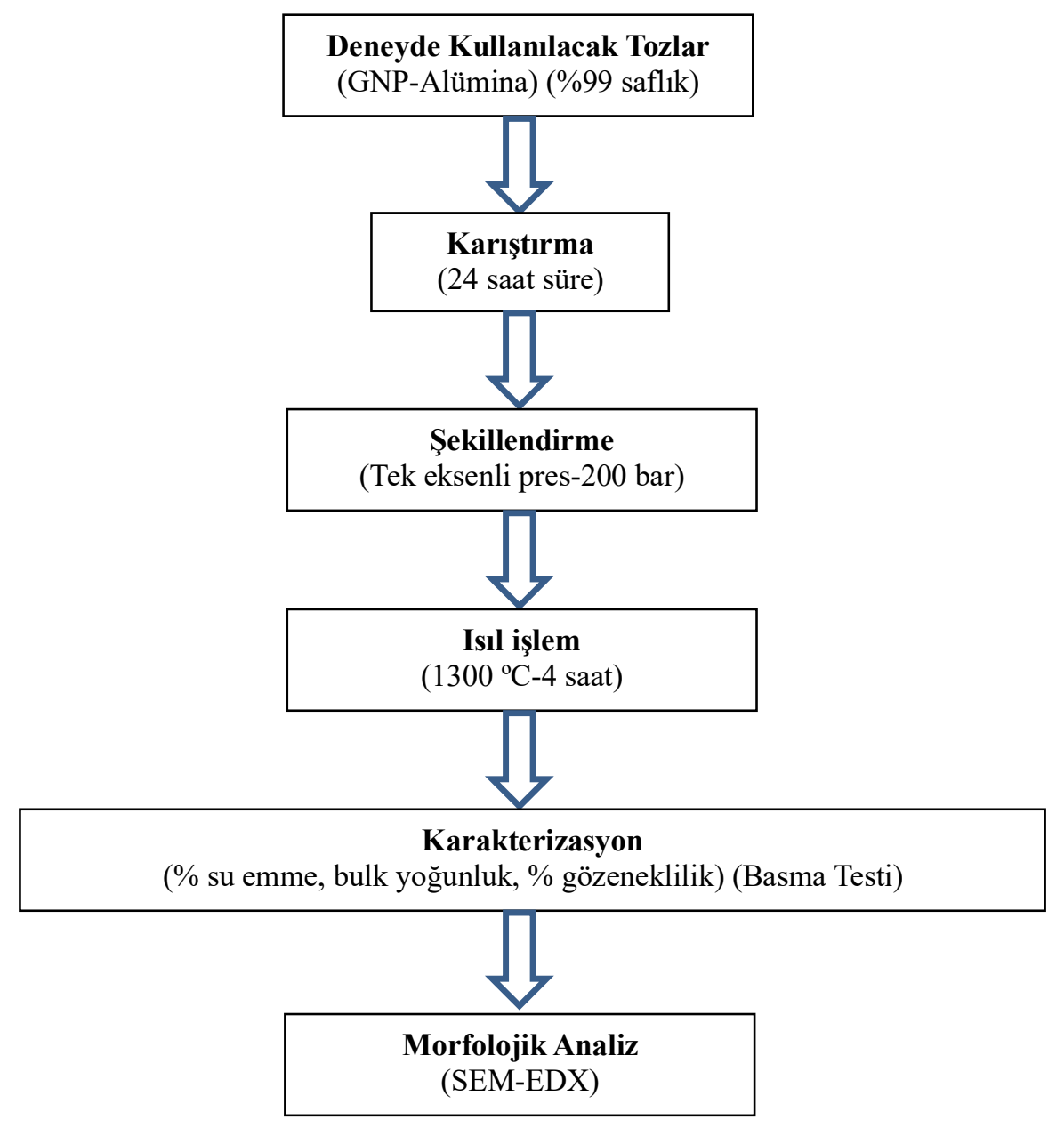

Şekil 1. Deneysel akış diyagramı

\section{Bulgular}

\section{1. \% Su Emme (Water Absorption)}

$\mathrm{Su}$ emme testi için Arşimet prensibinden yararlanılmıştır. $\mathrm{Bu}$ prensip aşağıdaki formüle göre hesaplanmaktadır (Şekil 2).

$$
\% \text { Su Emme }=\left[\left(W_{D}-W_{K}\right) / W_{K}\right] * 100
$$




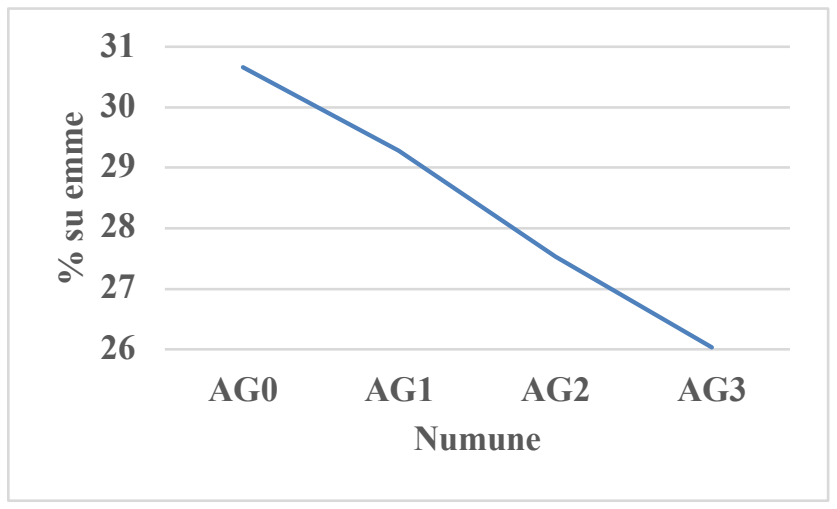

\begin{tabular}{|c|c|c|}
\hline Numune & Kod & $\begin{array}{c}\text { \% Su } \\
\text { emme }\end{array}$ \\
\hline Katkısız Alümina & AG0 & 30,66 \\
\hline \% 1 Grafen Katk11 & AG1 & 29,28 \\
\hline \% 2 Grafen Katk11 & AG2 & 27,53 \\
\hline \% 3 Grafen Katkılı & AG3 & 26,03 \\
\hline
\end{tabular}

Şekil 2. \% Su emme sonuçları

Burada, $\mathrm{W}_{\mathrm{K}}$ kuru numunenin havadaki ağırlığı (g), $\mathrm{W}_{\mathrm{D}}$ su ya da sıvı emdirilmiş (doymuş) numunenin havadaki ağırlı̆̆ $1 \mathrm{~g}$ ) olarak hesaplanmaktadır. Bu testte ilk önce numunelerin kuru ağırlıkları $\left(\mathrm{W}_{\mathrm{K}}\right)$ ölçülmüsştür. Kuru ağıllıkları ölçüldükten sonra numuneler yaklaşık $180^{\circ} \mathrm{C}$ 'lik su bulunan hazne içerisinde numuneler her saat başı ağırlıkları tartılmış ve ağırlıkları sabit oluncaya kadar bu işleme devam edilmiştir. Ortalama 4,5 saat süre sonrası tüm numunelerde değerler sabit hale gelmiştir. Bu süre zarfinda sonra 1sitılan numuneler soğumaya bırakılmıştır.

GNP katkı oranı arttıkça su emme değerlerinde azalmalar olmuştur. Bu durumun grafenin alümina yapı içerisinde sinterleme etkisiyle gözenekleri doldurduğunu göstermektedir. Gözeneklilik ile su emme doğru orantılıdır. Su emme değerleri azaldıkça gözeneklilik değerlerinde de azalmalar olmuştur.

\subsection{Bulk Yoğunluk (Bulk Density)}

Şekil 3’te bulk yoğunluk sonuçları görülmektedir. Bulk yoğunluk aşağıdaki formüle göre hesaplanmaktadır.

$$
\text { pbulk= }\left[W_{K} /\left(W_{D}-W_{A}\right)\right] x \rho s i v l
$$

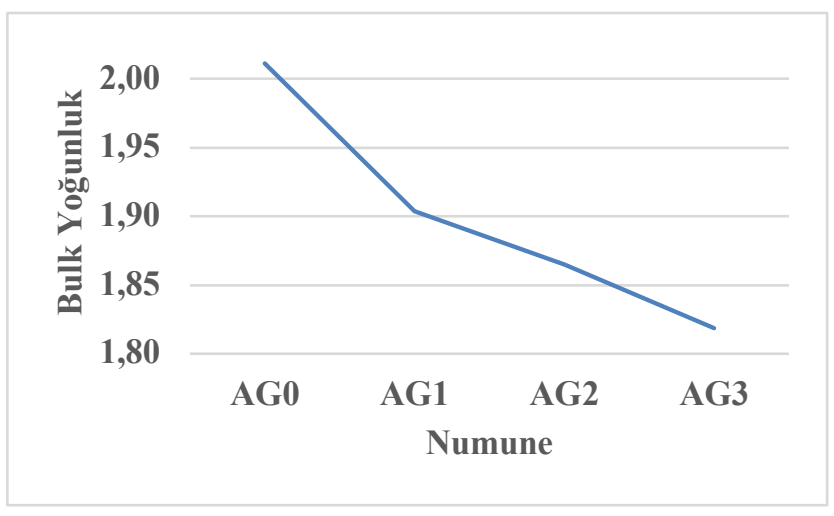

\begin{tabular}{|c|c|c|}
\hline Numune & Kod & $\begin{array}{c}\text { Bulk } \\
\text { Yoğunluk }\end{array}$ \\
\hline Katkısız Alümina & AG0 & 2,01 \\
\hline \% 1 Grafen Katkı1ı & AG1 & 1,90 \\
\hline \% 2 Grafen Katk11ı & AG2 & 1,88 \\
\hline \% 3 Grafen Katk111 & AG3 & 1,82 \\
\hline
\end{tabular}

Şekil 3. Bulk yoğunluk sonuçları 
Burada, $W_{A}$ su ya da sıvı emdirilmiş numunenin su içindeki asılı ağıllı̆̆ (g), $\rho$ sıvı ise Kullanılan sıvının (genellikle su) yoğunluğu olmaktadır. Su emme işleminde soğuma aşamasını takiben her bir numune Arşimet testi için özel olarak tasarlanmış düzenekte bulunan su içerisinde asılı kalarak ağırlıkları $\left(\mathrm{W}_{\mathrm{A}}\right)$ tartılmıştır. Asılı ağırlıkların belirlenmesinden sonra numune su içerisinden çıkarılır, yüzeyinde kalan artık su alınarak $80{ }^{\circ} \mathrm{C}$ 'lik etüv içerisinde kurutulmaya bırakılmıştır. Bu durum hem gözenekliliğin hem de yoğunluğun azalmasına katkı sağlaması açısından yapılmıştır. Bu işlem sonrası dışarı alınan numuneler tekrar terazide tartılmıştır $\left(\mathrm{W}_{\mathrm{D}}\right)$.

GNP katkısı ile birlikte bulk yoğunluklarda azalmalar olmuştur. Bu durum, kompozitlerde düşük yoğunluklu katkının kompozitin yoğunluğunu düşürmesine benzerdir. GNP yoğunluğu alümina yoğunluğundan daha düşüktür. Yapıdaki GNP miktarının artması dolayısıyla yoğunlukta düşmeye neden olacaktır.

\section{3. \% Gözeneklilik (Porosity)}

Şekil 4’te \% gözeneklilik testi sonuçları yer almaktadır. \% gözeneklilik testi aşağıda yer alan formüle göre hesaplanmıştır.

$$
\text { Porozite }=\left[\left(W_{D}-W_{K}\right) /\left(W_{D}-W_{A}\right)\right] * 100
$$

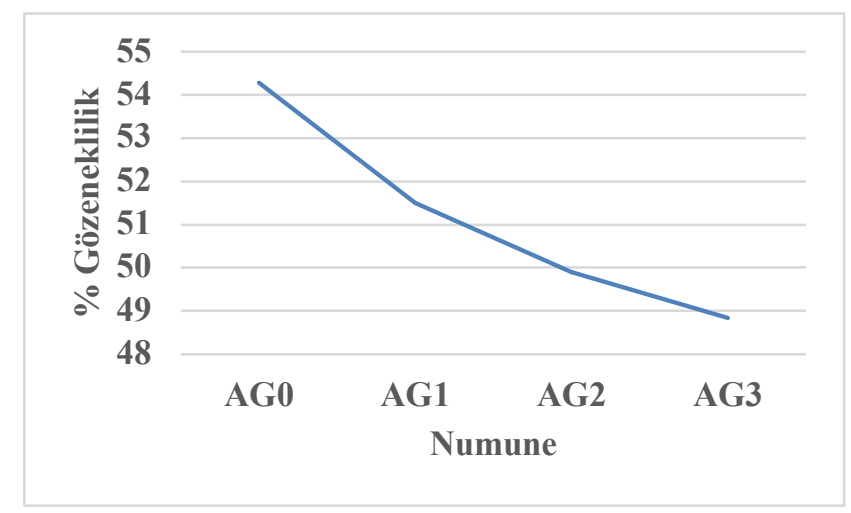

\begin{tabular}{|c|c|c|}
\hline Numune & Kod & $\begin{array}{c}\text { \% } \\
\text { Gözeneklilik }\end{array}$ \\
\hline Katk1s1z Alümina & AG0 & 54,28 \\
\hline \% 1 Grafen Katk1lı & AG1 & 51,50 \\
\hline \% 2 Grafen Katk1lı & AG2 & 49,90 \\
\hline \% 3 Grafen Katk1lı & AG3 & 48,84 \\
\hline
\end{tabular}

Şekil 4. \% Gözeneklilik sonuçları

Gözeneklilik değerlerinin literatürde $\% 50$ ve altında olması istenmektedir. Şekil 5'teki sonuçlara bakıldığında grafen katkılı karışımlarda katkı oranı arttıkça gözeneklilik azalmakta, bu durumda yapı içerisinde tanelerin homojen şekilde dağıldığını ve boşlukların azaldığını göstermektedir.

Sinterleme sıcaklığı ve süresinin dışında GNP katkı oranlarının artmasına bağlı olarak gözeneklik değerlerinde azalmalar olmuştur. Gözeneklilik yapı içerisinde genellikle istenmeyen bir durumdur. Gözeneklilik azalmasıyla tanelerin birbirine yapışması daha iyi hale gelmiş ve bu durum basma testi sonuçlarına da yansımıştır. 


\subsection{Basma Testi (Compression Test)}

Şekil 5'de katkısız alümina ve GNP katkılı numunelere 1sıl işlem sonrası gerçekleştirilen basma testi sonuçları yer almaktadır.

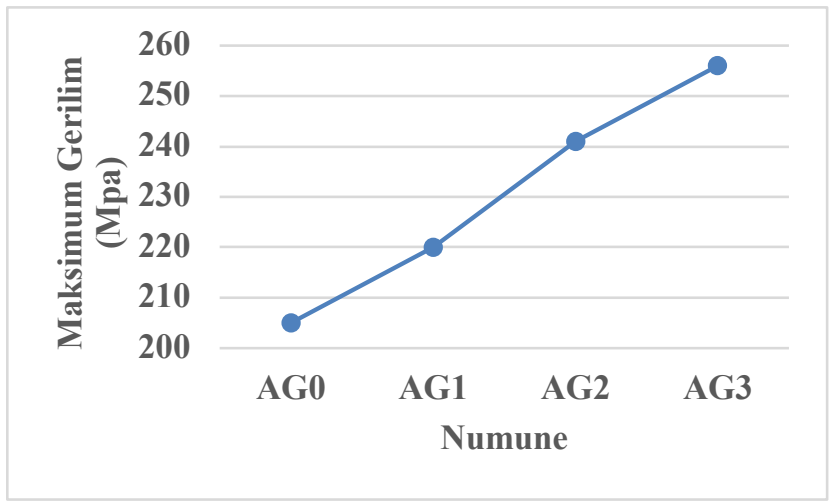

\begin{tabular}{|c|c|c|}
\hline Numune & Kod & $\begin{array}{c}\text { Basma } \\
\text { Testi } \\
\text { (MPa) }\end{array}$ \\
\hline Katkısı Alümina & AG0 & 205 \\
\hline \% 1 Grafen Katk1lı & AG1 & 220 \\
\hline \% 2 Grafen Katk11 & AG2 & 241 \\
\hline \% 3 Grafen Katk1lı & AG3 & 256 \\
\hline
\end{tabular}

Şekil 5. Basma test sonuçları

Sonuçlar incelendiğinde en yüksek değerler \% 3 grafen katkılı numunelerde $256 \mathrm{MPa}$ olarak bulunmuştur. GNP katkısının mekanik özelliklerde artış göstermesi beklenen bir durumdur. Bu etki sonuçlara da yansımış ve saf alüminaya göre değerlerde orantılı artışlar olmuştur. Tabaka halinde bulunan grafen sahip olduğu yüksek elastisite modülü sayesinde kompozitte mekanik özelliklerde artış göstermiştir. Gözenekli yapının azalması tanelerin sinterleme ve dolgu ile gözeneklerin küçüldüğünü, tanelerin birbirine iyice yapıştığını göstermektedir. Literatürde yapılan çalışmada alümina esaslı kompozitlere GNP takviye edilmiş ve sinterleme yapılarak mekanik özellikleri incelenmiştir. GNP katkısına göre sertlik değerlerinde de değişmeler olmuştur [19,20].

\subsection{Morfolojik Analiz (Morphological Analysis)}

Şekil 6'da saf alümina ve grafen katkılı numunelere ısıl işlem sonrasında yapılan SEM analiz görüntüleri görülmektedir. Sıcaklık ve süre etkisiyle yapı içerisinde tane dağılımları ve yapıları ortaya çıkmıştır. Şekil 6 a'da katkısız saf alümina tanecikleri sıcaklığın etkisiyle birbirine iyice yapışmıştır. Buna karşın yapı içerisinde boşluklarda meydana gelmiştir. Bu durumun yapılan karışmadan ve kalıp içerisinde presleme işleminden kaynaklandığı düşünülmektedir. Şekil 6 b, c ve d'de grafen katkılı numunelere ait görüntülerde katkı oranı arttıkça grafenin yapı içerisinde levha şeklinde oluştuğu görünmektedir. Kullanılan grafen tozu levha şeklindedir. Bu durum \% 2 ve \% 3 grafen katkılı yapılarda daha belirgin halde ortaya çıkmıştır. Liu ve arkadaşları (2012), Nieto ve arkadaşları (2016), yaptıkları çalışmalarda grafen nano levhalar kullanarak alümina esaslı kompozitler üretmişlerdir. Yaptıkları morfolojik analizlerde grafen katkı oranlarına göre nano levhaları belirgin olarak elde etmiş ve sonuçlarda bunu göstermişlerdir [21,22]. 


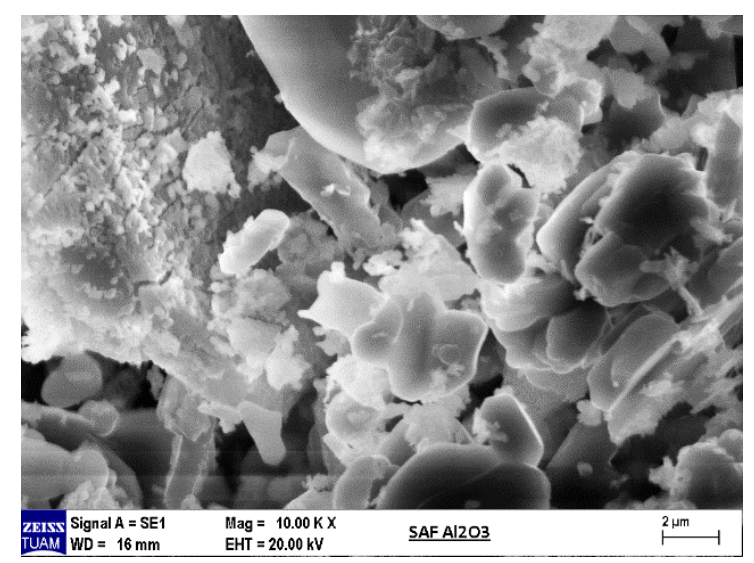

(a)

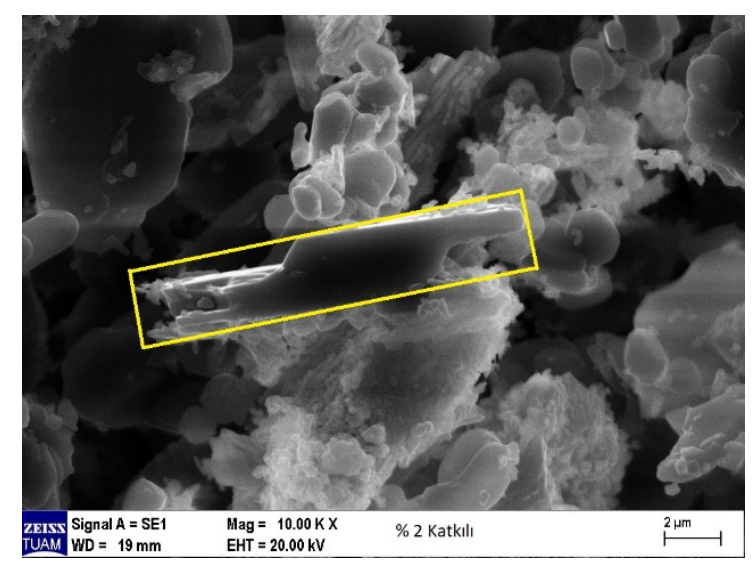

(c)

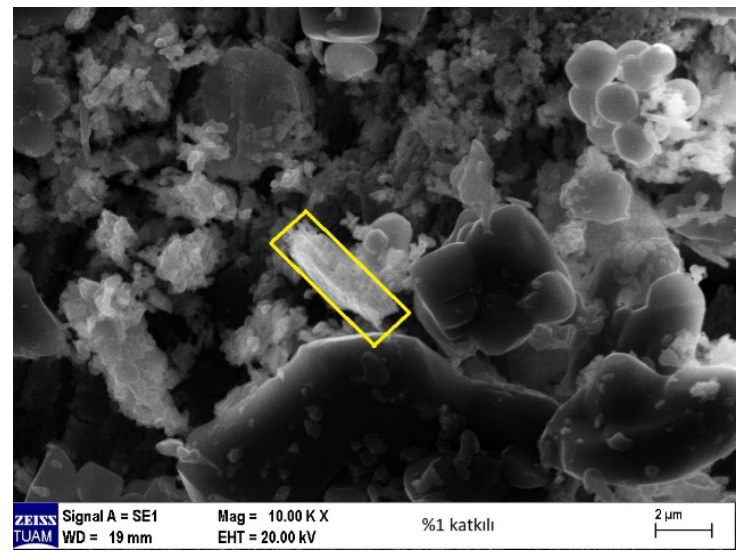

(b)

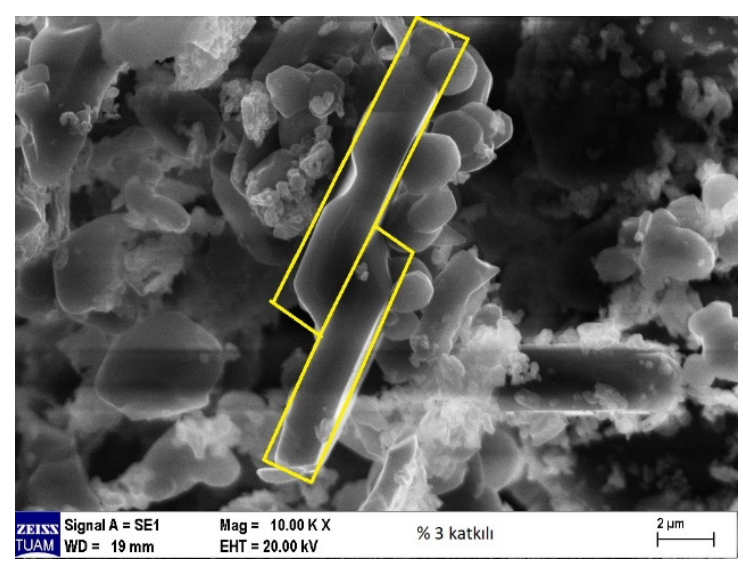

(d)

Şekil 6. SEM analiz sonuçları (a: Saf Alümina, b: \% 1 Grafen Katkılı, c: \% 2 Grafen Katkılı, d: \% 3 Grafen Katk1l1)

Şekil 7 a ve d'de saf alümina ve grafen katkılı numunelere yapılan EDX analiz sonuçları yer almaktadır. GNP'nin karbondan meydana gelmesi nedeniyle analiz sonucunda $\mathrm{C}$ piki ortaya çıkmıştır. 


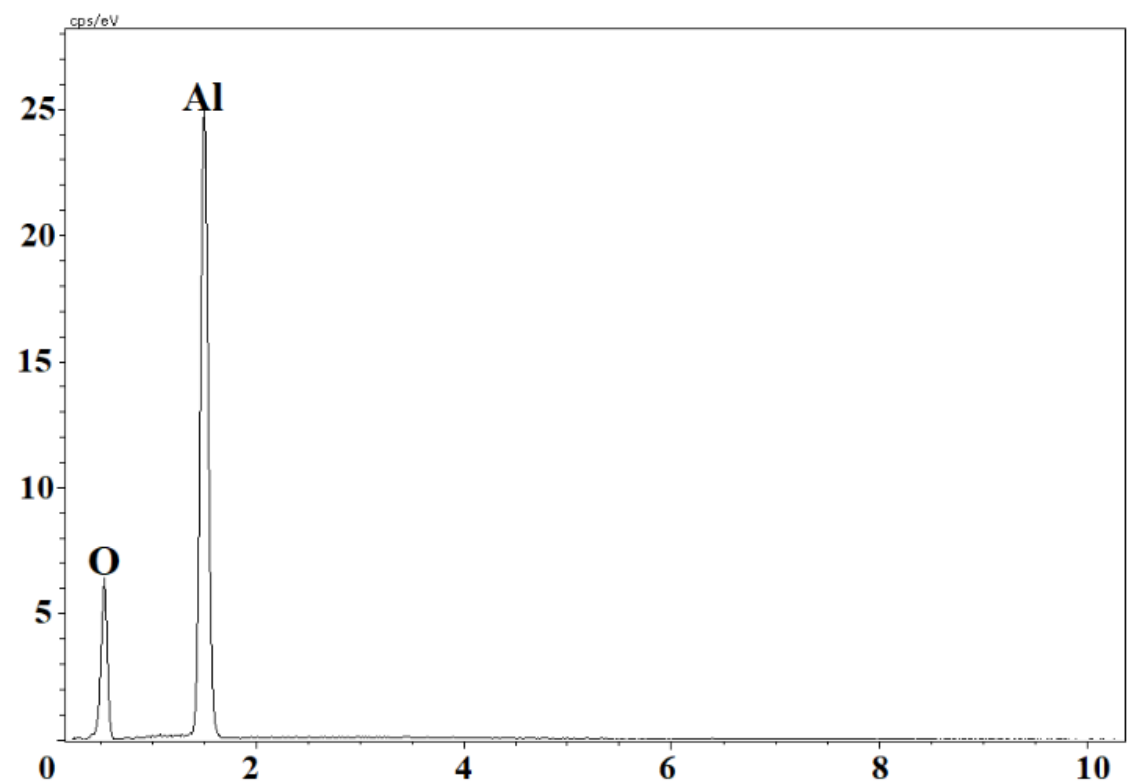

(a)

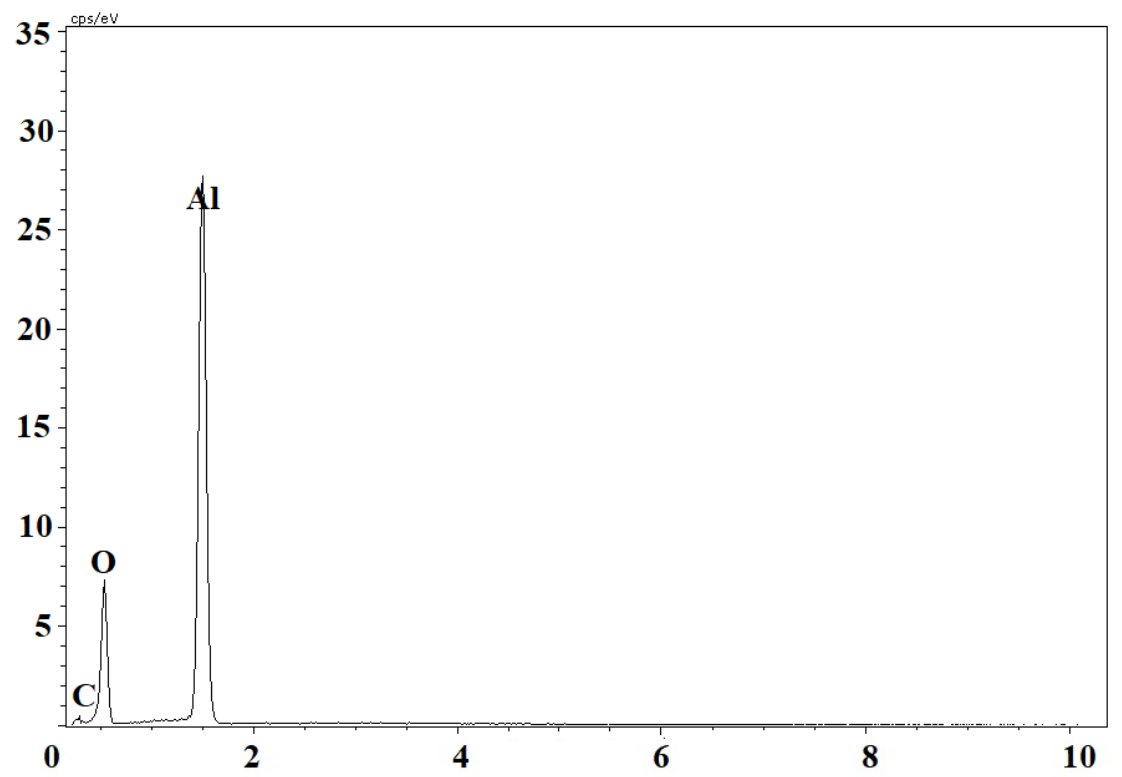

(b)

Şekil 7. EDX analiz sonuçları (a: Saf Alümina, b: Grafen Katkılı)

\section{Sonuçlar ve Tartışma}

GNP katlılı alümina seramikler gözenekli formda üretilmiştir. Tek eksenli hidrolik preste 200 bar basınçta şekillendirilmiş olsa da gözenekli bir yapı ortaya çıkmıştır. Bunun iki nedeni olabilir. Bunlardan birincisi GNP'nin saf olmaması ve ısıl işlem sırasında oksidasyona uğrayarak yapıdan karbondioksit veya karbonmonoksit olarak uzaklaşmasıdır. Böylece GNP'nin bıraktı̆̆ı bölgeler gözenek olarak kalmış olabilir. İkinci nedeni ise şekillendirme yönteminin basıncının yetersiz gelmesi, daha yüksek sıcaklıklarda sinterlemeye ihtiyaç duyulmasıdır. 
GNP katkılı kompozitte yüksek su emme ve gözeneklilik olmasına rağmen mekanik özelliklerinin katk1 miktarının artmasıyla yükselmesi olumlu yanıdır. Hem gözenekli ve hem de mukavemetli yapılar kendilerine değişik kullanım alanları bulabilir. Özellikle gaz sensörleri, membran filtreler, ayırma prosesleri için vazgeçilmez bir ürün olabilir.

\section{Teşekkür}

$\mathrm{Bu}$ çalışma, Afyon Kocatepe Üniversitesi Bilimsel Araştırma Koordinasyon Birimi (BAPK) 19.FEN.BİL.40 numaralı tez projesi ile desteklenmiştir.

\section{Kaynaklar}

[1] S. Solakoglu, "Toz Metalurjisi Yöntemi ile Üretilen Uçucu Kül Takviyeli Alüminyum Matrisli Kompozitlerin Aşınma Davranışlarının İncelenmesi”, Yüksek Lisans Tezi, Karabük Üniversitesi, Karabük, Türkiye, 2021.

[2] I. Yildiz, A. G. Celik, and Gunes, I., "Characterization and Diffusion Kinetics of borided Ni-Mg Alloys", Protection of Metals and Physical Chemistry of Surfaces, vol. 56, No. 5, pp. 1015-1022, 2020.

[3] O. Yöntem, "Toz Metalurjisi ile Üretilen Alüminyum Matrisli Kompozitlerde Bor Minerali İlavesinin Mekanik Özelliklere Etkisinin Deneysel Tasarım Yöntemleri ile İncelenmesi”, Yüksek Lisans Tezi, Kocaeli Üniversitesi, Kocaeli, Türkiye, 2019.

[4] A. N. Tanrıverdi, “Toz Metalurjisi ile Üretilen Demir Matrisli Metallere Grafen ve Grafit İlavesinin Mikroyapı ve Mekanik Özelliklere Etkisinin Karşılaştırılması”, Yüksek Lisans Tezi, Karabük Üniversitesi, Karabük, Türkiye, 2021.

[5] Y. Shigeta, M. Aramaki, K. Ashizuka, Y. Ikoma, and Y. Ozaki, "Effect of networked $\mathrm{Cu}$-rich ferrite phase on proof stress and ultimate tensile strength of sintered bodies of $\mathrm{Fe}-\mathrm{Cu}$ hybrid-alloyed steel powder with graphite", Powder Metallurgy, vol. 64, pp. 134$141,2021$.

[6] M. Oktay, "Effects of Particle Granulation Optimisation and New Binder Development on Properties of Alumina Based Castable Refractories", M.Sc. Thesis, Istanbul Technical University, Istanbul, Turkey, 2018.

[7] S. H. Apaydın, "Zirkonya Takviyeli Alümina Esaslı Seramik Malzemelerin Üretimi ve Karakterizasyonu", Yüksek Lisans Tezi, On Dokuz Mayıs Üniversitesi, Samsun, Türkiye, 2018.

[8] Ş. Ş. Koçer, "Alümina Esaslı Hammadde ve Atıklardan Alümina Esaslı Aerojel Tozu Üretimi ve Karakterizasyonu”, Yüksek Lisans Tezi, Sakarya Üniversitesi, Sakarya, Türkiye, 2019.

[9] Q. Cao, Z. Wang, W. He, and Y. Guan, "Fabrication of super hydrophilic surface on alumina ceramic by ultrafast laser microprocessing", Applied Surface Science, In Press. 
[10] X. Y. Jiang, J. Hu, S. L. Jiang, X. Wang, L. B .Zhang, Q. Li, H. P. Lu, L. J. Yin, J. L. Xie, and L. J. Deng, "Effect of high-enthalpy atmospheric plasma spraying parameters on the mechanical and wear resistant properties of alumina ceramic coatings", Surface and Coating Technology, In Press.

[11] M. Hrubovčáková, E. Múdra, R. Bureš, A. Kovalčíková, R. Sedlák, V. Girman, and P. Hvizdoš, "Microstructure, fracture behaviour and mechanical properties of conductive alumina based composites manufactured by SPS from graphenated $\mathrm{Al}_{2} \mathrm{O}_{3}$ powders", Journal of the European Ceramic Society, vol. 40, pp. 4818-4824, 2020.

[12] A. J.M. Araújo, H. P. A. Alves, R. M. Andrade, L. F. A. Campos, D. A. Macedo, A. L. S. Pinho, R. M. Nascimento, and C. A. Paskocimas, "Designing experiments for the optimization of solid-state synthesis and characterization of alumina-based composites", Ceramics International, vol., pp. 8525-8532, 2019.

[13] B. Zhao, I. Khader, H. Liu, T. Zhou, G. Konrath, and A. Kailer, "Tribological characterization of an alumina-based composite in dry sliding contact against laser-heated and unheated Inconel 718”, Tribology International, vol. 155, pp. 106773, 2021.

[14] K. Lin, Y. Fang, D. Gu, Q. Ge, and J. Zhuang, L. Xi, "Selective laser melting of graphene reinforced titanium matrix composites: Powder preparation and its formability", Advanced Powder Technology, In Press.

[15] S. Marchesini, P. Turner, K. R. Paton, B. P. Reed, B. Brennan, K. Koziol, and A. J. Pollard, "Gas physisorption measurements as a quality control tool for the properties of graphene/graphite powders”, Carbon, vol. 167, pp. 585-595, 2020.

[16] Y. H. Kim, B. H. Park, Y. J. Choi, G. W. Lee, H. K. Kim, and K. B. Kim, "Compact graphene powders with high volumetric capacitance: Microspherical assembly of graphene via surface modification using cyanamide", Energy Storage Materials, vol. 24, pp. 351-361, 2020.

[17] S. H. Duntua, F. Tetteh, I. Ahmad, M. Islam, and S. Boakye-Yiadom, "Characterization of the structure and properties of processed aluminagraphene and alumina-zirconia composites”, Ceramics International, vol. 47, pp. 367-380, 2021.

[18] F. Gutiérrez-Mora, R. Cano-Crespo, A. Rincón, R. Moreno, and A. DomínguezRodríguez, "Friction and wear behavior of alumina-based graphene and CNFs composites", Journal of the European Ceramic Society, vol. 37, pp. 3805-3812, 2017.

[19] A. G. Zholnin, E. A. Klyatskina, E. G. Grigoryev, M. D. Salvador, A. A. Misochenko, P. L. Dobrokhotov, M. G. Isaenkova, M. A. Sinaysky, and V. V. Stolyarov, "Spark-Plasma Sintering of $\mathrm{Al}_{2} \mathrm{O}_{3}$-Graphene Nanocomposite", Inorganic Materials: Applied Research, vol. 9 (3), pp. 498-503, 2018.

[20] A. Altintaş, U. Çavdar, İ. M. Kuşoğlu, “The Effect of Graphene Nanoplatelets on the Wear Properties of High Frequency Induction Sintered Alumina Nanocomposites", Journal of Inorganic and Organometallic Polymers and Materials, vol. 29, pp. 667-675, 2019. 
[21] J. Liu, H. Yan, M. J. Reece, K. Jiang, “Toughening of zirconia/alumina composites by the addition of graphene platelets", Journal of the European Ceramic Society, vol. 32, pp. 4185-4193, 2012.

[22] A. Nieto, J. M. Zhao, Y. H. Han, K. H. Hwang, J. M. Schoenung, "Microscale tribological behavior and in vitro biocompatibility of graphene nanoplatelet reinforced alümina", Journal of The Mechanical Behavior of Biomedical Materials, vol. 61, pp. 122134, 2016. 